\title{
Capnometry and the paediatric laryngeal mask airway
}

\author{
I.A. Spahr-Schopfer MD, B. Bissonnette MD, \\ E.J. Hartley MD
}

The laryngeal mask airway (LMA), an alternative to tracheal intubation in certain situations, has gained popularity in recent years. Initially designed for use in adults it has now become available in suitable sizes for paediatric anaesthesia. The objectives of this study were to identify the preferred site of sampling the end-tidal carbon dioxide $\left(\mathrm{PETCO}_{2}\right)$ with the $L M A$ and to determine the accuracy of this recording when compared with arterial $\mathrm{CO}_{2}\left(\mathrm{PaCO}_{2}\right)$. We studied 30 healthy children, age one to five years and weighing between 10 and $25 \mathrm{~kg}$ undergoing minor surgery requiring mask anaesthesia. In each case, after induction of anaesthesia, the LMA was inserted under direct vision to eliminate the possibility of epiglottic airway obstruction. The fresh gas flow was provided by a Jackson Rees modification of an Ayre's T-piece and was determined according to the following formula: $3 \times(1000+(100 \times$ body weight)) LPM. Blood pressure, ECG, $\mathrm{O}_{2}$ saturation, temperature and end-tidal gas concentrations were recorded. The measures of peak $\mathrm{PETCO}_{2}$ were taken at pre-determined distances from the elbow connector down the LMA shaft. During the sampling sequence an arterial blood sample was taken for gas analysis. The $\mathrm{PaCO}_{2}$ was $63.5 \pm 9.3 \mathrm{~mm} \mathrm{Hg}$ (mean $\pm \mathrm{SD}$ ). At any given sampling site, mean $\mathrm{PETCO}_{2}$ values were less than $\mathrm{PaCO}_{2}(\mathrm{P}<0.05)$. However, in eight patients $\mathrm{PETCO} \mathrm{O}_{2}$ values measured at the distal site were higher than the $\mathrm{PaCO}_{2}$ (negative $P(a-E T) C_{2}$ gradients). The results of this study suggest that when the LMA is used in children undergoing minor surgery who are spontaneously breathing halothane, the $\mathrm{PETCO}$ values obtained from different sites underestimate the value of the $\mathrm{PaCO}_{2}$. The preferred site for measuring $\mathrm{PETCO}_{2}$ in these children is the distal end of the shaft although this value is less

\section{Key words}

ANAESTHESIA: paediatric;

CARBON DIOXIDE: end tidal;

EQUIPMENT: laryngeal mask;

MEASUREMENT TECHNIQUES: capnometry.

From the Department of Anaesthesia, The Hospital for Sick Children, 555 University Avenue, Toronto, Ontario, Canada.

Presented in part at the 49th annual meeting of the CAS, June 1992, Toronto, Ontario, Canada.

Address correspondence to: Dr. E.J. Hartley, Department of Anaesthesia, The Hospital for Sick Children, 555 University Avenue, Toronto, Ontario, Canada MSG 1 X8. than $\mathrm{PaCO}_{2}(P<0.05)$. In addition, use of the LMA does not prevent the hypercapnia associated with halothane anaesthesia in children breathing spontaneously.

De plus en plus utilisé depuis quelques années, le masque laryngé permet dans certains cas d'éviter lintubation. Destiné d'abord aux adultes, il est maintenant disponible en plusieurs grandeurs pour usage pédiatrique. Cette étude vise à trouver sur le masque laryngé le site d'échantillionnage idéal pour le gaz carbonique téléexpiratoire $\left(\mathrm{PETCO}_{2}\right)$ et évaluer la précision de cette mesure comparativement au $\mathrm{CO}_{2}$ artériel $\left(\mathrm{PaCO}_{2}\right)$. Trente enfants âgés d'un à cinq ans et pesant de 10 à $25 \mathrm{~kg}$. programmés pour une intervention chirurgicale mineure avec anesthésie au masque, font partie de l'étude. Dans chacun des cas, le masque laryngé est inséré sous vision directe pour éliminer toute possibilité d'obstruction par l'épiglotte. Les gaz frais sont fournis par un tube en $T$ d'Ayre modifié par Jackson Rees avec un débit calculé selon la formule suivante: $3 \times(1000$ $+(100 \times$ poids $)) L \cdot \mathrm{min}^{-1}$. La pression artérielle, l'ECG, la saturation, la température et les concentrations téléexpiratoires sont enregistrées. Les échantillons de $\mathrm{PETCO}_{2}$ sont prélevées à distances prédéterminées du raccord le long de la tubulure fixée au masque laryngé. En même temps que la capnométrie, on prélève un echantillon de sang pour lanalyse des gaz artériels. $\mathrm{La} \mathrm{PaCO}$ est de 63,5 $\pm 9,3 \mathrm{~mm} \mathrm{Hg}$ (moyenne $\pm E T$ ). $A$ chacun des sites d'échantillonnage gazeux, les valeurs moyennes de $\mathrm{PETCO}_{2}$ sont moindres que la $\mathrm{PaCO}_{2}(P<0,05)$. Cependant, chez huit patients, au site le plus distal, les valeurs de $\mathrm{PETCO}_{2}$ dépassent la $\mathrm{PaCO}_{2}$ (gradient $\mathrm{P}(a-E T) \mathrm{CO}_{2}$ négati). Les résultats de cette étude suggèrent que l'usage du masque laryngé, chez l'enfant soumis à une chirurgie mineure sous anesthésie à lhalothane en ventilation spontanée, procure des mesures de $\mathrm{PETCO}_{2}$ qui sous-estiment la $\mathrm{PaCO}_{2}$. Chez ces enfants, il est préférable de prélever les échantillons de $\mathrm{PETCO}_{2}$ à la partie distale de la tubulure fixe du masque bien que cette valeur soit moins élevée que la $\mathrm{PaCO}_{2}(P<0,05)$. Lutilisation du masque laryngé ne prévient pas non plus Ihypercapnie associée à l'anesthésise à l'halothane en ventilation spontanée.

Capnometry and capnography are required in patients whose tracheas are intubated during general anaesthesia. ${ }^{1}$ An accurate measurement of end-tidal $\mathrm{CO}_{2}\left(\mathrm{PETCO}_{2}\right)$ is difficult to determine in infants and children due to a 
combination of high fresh gas flows and small tidal volumes. $^{2}$ Using a mass spectrometer with a continuous sampling technique, Kaplan and Paulus demonstrated that fresh gas flows continuously through the Mapleson $F$ circuit (such as a Jackson-Rees' modification of Ayre's T-piece) during inspiration and expiration. ${ }^{3}$ They suggested that the fresh gas flow could contaminate the exhaled gases, dilute them and lead to inaccurate estimates of end-tidal gas concentrations. Fletcher has suggested that the $\mathrm{P}(\mathrm{a}-\mathrm{ET}) \mathrm{CO}_{2}$ gradient is lower at large tidal volumes. ${ }^{4} \mathrm{He}$ concluded that the presence of a large $\mathrm{P}(\mathrm{a}-\mathrm{ET}) \mathrm{CO}_{2}$ gradient indicates a low efficiency of ventilation similar to that observed at small tidal volumes. These factors produce dilution of the $\mathrm{PETCO}_{2}$ and a consequent underestimation of the arterial carbon dioxide partial pressure $\left(\mathrm{PaCO}_{2}\right)$. Several studies have suggested alternatives to circumvent this problem. ${ }^{5-7}$ Sampling the $\mathrm{PETCO}_{2}$ at the distal end of the endotracheal tube was shown to improve the accuracy of $\mathrm{PETCO}_{2}$ in estimating $\mathrm{PaCO}_{2}$ in small infants of $<12 \mathrm{~kg}$. ${ }^{5}$ Recently, a laboratory study visualizing the mixing of fresh gas and expired gas in the Mapleson D circuit showed that, regardless of fresh gas flow rates, the site of mixing is always proximal to the point of narrowing of the endotracheal tube connector. ${ }^{8}$ It confirms the result of two previous investigations which suggested that $\mathrm{PETCO}_{2}$ sampling immediately below the connector with a needle inserted through the endotracheal tube wall was sufficient to estimate the $\mathrm{PaCO}_{2}{ }^{9-10}$

Because the laryngeal mask airway has a large shaft, it is possible that the dilutional effect caused by the fresh gas flow may be more important than that which is reported with an endotracheal tube. This study was therefore designed to determine the preferred site of sampling of end-tidal $\mathrm{CO}_{2}$ and the accuracy of this site as an estimate of $\mathrm{PaCO}_{2}$ in anaesthetized infants and children breathing spontaneously through a laryngeal mask airway.

\footnotetext{
Methods

After approval by the Human Subject Review Committee and obtaining informed parental consent, 30 unpremedicated healthy infants and children, ASA physical status I and II, weighing between 6.5 and $25 \mathrm{~kg}$ were enrolled in the study. The infants and children were fasted for three hours. All patients were scheduled for elective minor surgery requiring general mask anaesthesia and lasting less than one hour. Patients with abnormal airway anatomy or known to have cardiopulmonary disease were excluded. All children were supine and were monitored with a blood pressure cuff, ECG, transcutaneous oxygen saturation, and end-tidal gas monitor and an axillary temperature probe. Following administration of atropine
}

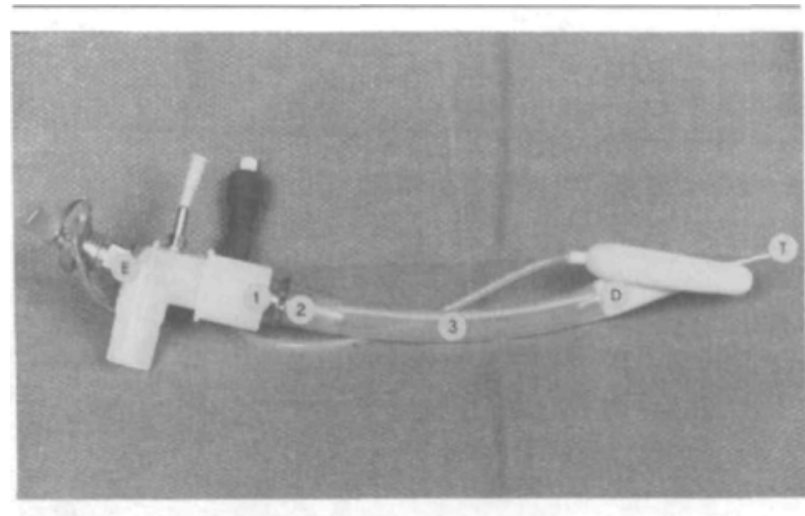

FIGURE I A size \#2 laryngeal mask airway was used. The elbow connector was modified and the modification consisted of two ports which allowed placement of a flexible fibreoptic and an $\mathrm{ETCO}_{2}$ sampling catheter. Sampling sites are as follows; $\mathrm{E}=$ elbow; $1,2,3=$ $4.5,6,11 \mathrm{~cm}$ from the elbow; $\mathrm{D}=$ distal $(17 \mathrm{~cm}$ from the elbow); $\mathrm{T}=$ tracheal ( $3 \mathrm{~cm}$ into the trachea).

$0.02 \mathrm{mg} \cdot \mathrm{kg}^{-1}$ iv anaesthesia was induced with either thiopentone $5 \mathrm{mg} \cdot \mathrm{kg}^{-1} i v$ or halothane (in increments of $0.5 \%$ up to $3 \%$ ) by mask. Anaesthesia was maintained with halothane and $70 \% \mathrm{~N}_{2} \mathrm{O}$ in $\mathrm{O}_{2}$. Spontaneous respiration was allowed in all cases.

A size \#2 laryngeal mask airway was inserted under direct vision to ensure its correct placement. The elbow connector (Gybeck-Dryden Corporation, Indianapolis, IN) was modified by the addition of two ports which allowed placement of a flexible fibreoptic bronchoscopy and an $\mathrm{ETCO}_{2}$ sampling catheter (Figure 1). The fresh gas flow was provided by means of a Mapleson F circuit (Jackson-Rees' modification of an Ayre's T-piece) and was determined according to the formula: $3 \times(1000+$ $(100 \times$ body weight in $\mathrm{kg}$ )) LPM. "If rebreathing was observed on the capnometer the fresh gas flow was increased until it could be eliminated. The end-tidal carbon dioxide partial pressures were recorded at steady-state by a Puritan-Bennett/Datex 255 infrared sidestream capnometer (Datex Instrumentarium Corp., Helsinki, Finland) calibrated before each study with dry gas of known composition $\left(5 \% \mathrm{CO}_{2}\right.$ and $\left.36 \% \mathrm{~N}_{2} \mathrm{O}\right)$. All values of PETCO ${ }_{2}$ were corrected for BTPS. ${ }^{12}$ The measurements of peak end-tidal $\mathrm{CO}_{2}$ were taken in random order at predetermined distances from the elbow connector down the LMA shaft using a \#19 standard-wire gauge Deseret Intracath (Beckton Dickinson Deseret Medical, Sandy, UT) inserted through the lateral Luer lock port at the elbow connector. If respiration was cyclical the highest $\mathrm{PETCO}_{2}$ was recorded for analysis. Samples were taken proximally at the elbow connector and distally from the elbow connector at levels of $4.5 \mathrm{~cm}, 6 \mathrm{~cm}, 11 \mathrm{~cm}, 17$ $\mathrm{cm}$ (the distal end of the laryngeal mask airway) and 
$20 \mathrm{~cm}(3 \mathrm{~cm}$ into the trachea) (Figure 1). During the sampling sequence an arterial blood gas was drawn from each patient by radial stab. Respiratory rate and tidal volumes were measured by means of a Wright Pediatric Respirometer (Ohmeda, Mississauga, Ontario).

\section{Statistical analysis}

All demographic and parametric data are expressed as mean \pm standard deviation (SD). The normally distributed data were analyzed with repeated-measures ANOVA and the Student-Neuman-Keuls tests for multiple comparisons. $P<0.05$ was accepted. The degree of agreement between measurements at the proximal and distal sites and arterial $\mathrm{PCO}_{2}$ was calculated using the method of Bland and Altman. ${ }^{13}$ We decided, a priori, that a clinically acceptable range of deviation from the "true" $\mathrm{CO}_{2}$ value $\left(\mathrm{PaCO}_{2}\right)$ would be $\pm 5 \mathrm{mmHg}$, i.e., a $\mathrm{PETCO}$ measurement in the range of $35-45 \mathrm{mmHg}$ would be acceptable for a $\mathrm{PaCO}_{2}$ value of $40 \mathrm{mmHg}$. Subsequently, from prospectively collected $\mathrm{PETCO}_{2}$ measurements, the 95\% confidence interval between paired $\mathrm{CO}_{2}$ measurements was calculated by the mean $\pm 2 \mathrm{SD}$. Assuming a normal distribution, $95 \%$ of the differences between paired $\mathrm{CO}_{2}$ would fall within the range of mean +2 SD and mean -2 SD. If this calculated $95 \%$ confidence interval falls within the previously set clinically acceptable range, the degree of agreement between the two methods is considered to be good. Coefficients of determination $\left(\mathrm{r}^{2}\right)$ for the $\mathrm{PETCO}_{2}$ recorded at the proximal and distal site were compared to $\mathrm{PaCO}_{2}$ using a linear regression analysis. Both coefficients of determination were compared using an unpaired $t$ test. The two different analyses were chosen to show that the coefficient of determination measures the strength of relationship between the two variables, not the agreement between them.

\section{Results}

The age and weight of the children were $3.9 \pm 1.5 \mathrm{yr}$ and $16.6 \pm 3.6 \mathrm{~kg}$ respectively. The mean respiratory rate was $45 \pm 8 \cdot \mathrm{min}^{-1}$ and the mean tidal volume was $2.2 \pm 0.7 \mathrm{ml} \cdot \mathrm{kg}^{-1} \cdot \mathrm{breath}^{-1}$. At the distal and tracheal sampling sites, rebreathing of $4-5 \mathrm{mmHg} \mathrm{CO}$ was noted which could not be eliminated by increasing the fresh gas flow. The preset fresh gas flow was sufficient to avoid rebreathing at any of the other sampling sites.

The mean $\mathrm{PaCO}_{2}$ measured by a single arterial stab during the sampling sequence was $63.5 \pm 9.3 \mathrm{mmHg}$. Measured $\mathrm{PETCO}_{2}$ rose progressively as sampling became more distal from the elbow (Figure 2). Mean $\mathrm{PETCO}_{2}$ values measured at each sampling site were less than the $\mathrm{PaCO}_{2}(P<0.05)$. The coefficient of determinations $\left(\mathrm{r}^{2}\right)$ for the proximal (E and the distal (D) sites (Figure 1) were 0.20 and 0.50 respectively and they were different

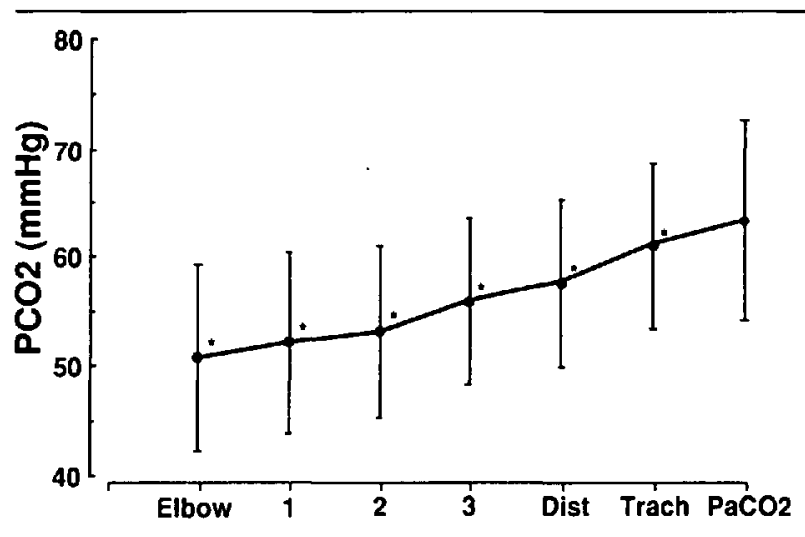

FIGURE 2 The mean ( $\pm \mathrm{SD}$ ) for end-tidal $\mathrm{CO}_{2}$ measurements obtained at predetermined distances from the elbow connector down to the distal end of the laryngeal mask airway and within the trachea. ${ }^{*} P<0.05$ represent each site compared to $\mathrm{PaCO}_{2}$.

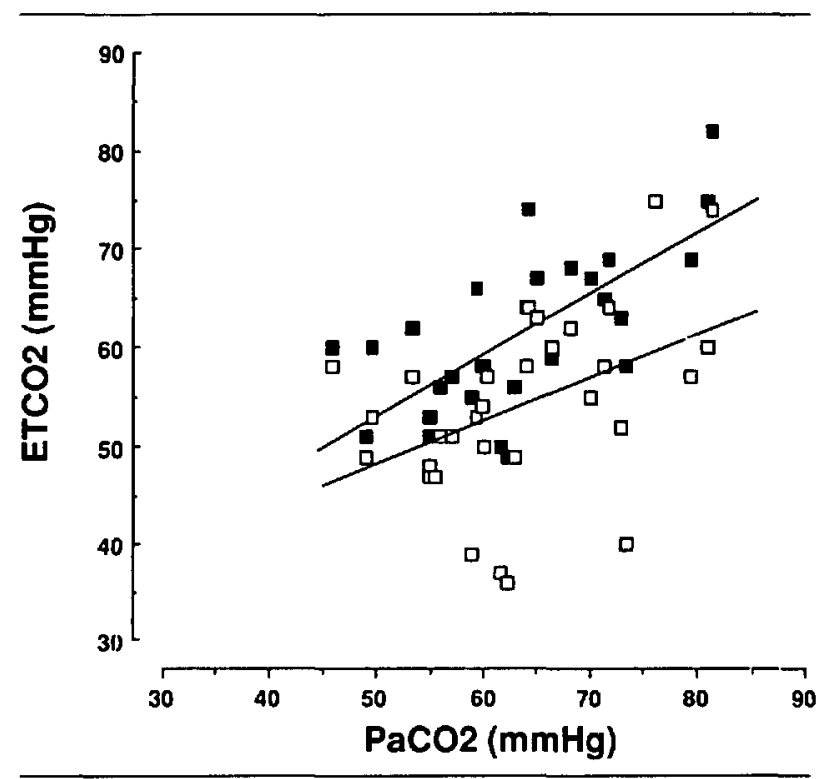

FIGURE $3 \quad \operatorname{PETCO}_{2}(\mathrm{mmHg}$ ) ( distal and $\square$ proximal) measurements are plotted against the $\mathrm{PaCO}_{2}(\mathrm{mmHg})$. The coefficient of determination $\left(r^{2}\right)$ for distal and proximal were 0.5 and 0.2 respectively.

$(P<0.05)$ (Figure 3). The paired mean difference between the airway capnometry $\mathrm{CO}_{2}$ and the $\mathrm{PaCO}_{2}$ for the proximal site was $9.34 \pm 9.9 \mathrm{mmHg}$ with $95 \%$ confidence interval 2.94 to $15.74 \mathrm{mmHg}$ (Figure 4). Figure 5 shows the same graphical analysis for distal $\mathrm{PETCO}_{2}$. The mean difference was $2.02 \pm 6.9 \mathrm{mmHg}$, $95 \%$ confidence interval from -2.46 to $6.50 \mathrm{mmHg}$. There was no correlation between the weight of the children and the gradient between arterial and end-tidal $\mathrm{PCO}_{2}$ values whether measured at the proximal or distal sites.

One child developed a brief episode of laryngospasm during LMA insertion which was treated with positive 


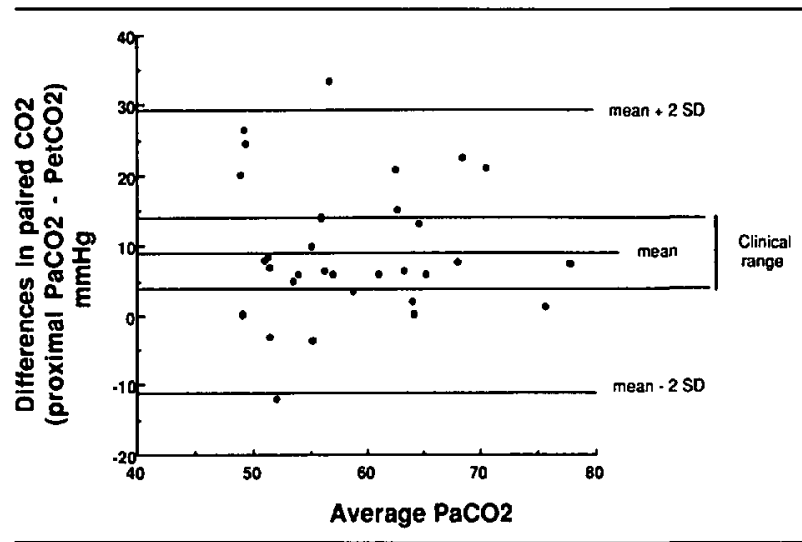

FIGURE 4 The differences in paired proximal end-tidal $\mathrm{CO}_{2}$ measurements are plotted against $\mathrm{PaCO}_{2}$. The mean, mean $+2 \mathrm{D}$ and mean $-2 S D$ values are shown in the graph.

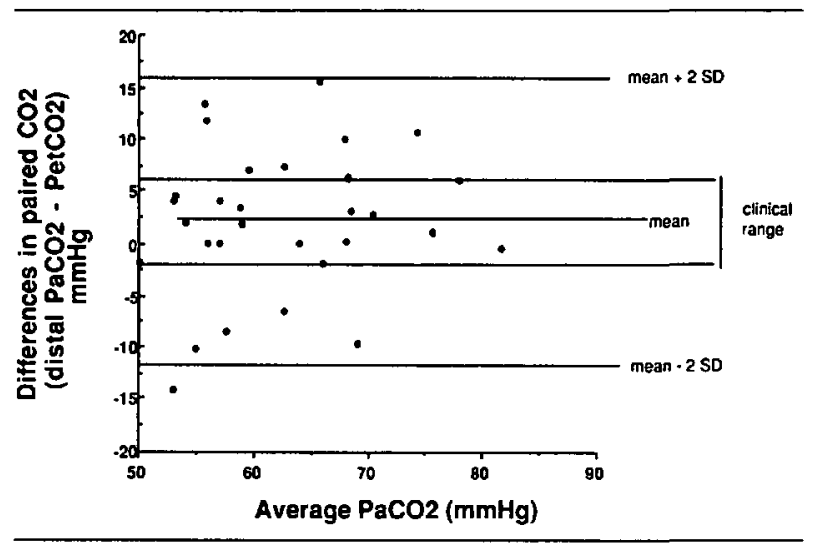

FIGURE 5 The differences in paired distal end-tidal $\mathrm{CO}_{2}$ measurements are plotted against $\mathrm{PaCO}_{2}$. The mean, mean $+2 \mathrm{D}$ and mean $-2 S D$ values are shown in the graph.

pressure ventilation. There were no other episodes of oxygen desaturation due to placement or removal of the laryngeal mask airway. There were no complications as a result of this study.

\section{Discussion}

The results of this study show the $\mathrm{PETCO}_{2}$ values measured at different sites in the LMA are less than the $\mathrm{PaCO}_{2}$ in children breathing halothane spontaneously $(P<$ 0.05). The best approximation of the $\mathrm{PaCO}_{2}$ is the $\mathrm{PETCO}_{2}$ value measured at the distal end of the shaft of the LMA but the correlation remains poor (coefficient of determination $\left.\left(r^{2}\right)=0.5\right)$.

The use of capnometry is recognized as a means of estimating $\mathrm{PaCO}_{2}$ in adults. In infants and children, however, $\mathrm{PETCO}_{2}$ measurement is more difficult and its value as a means of estimating $\mathrm{PaCO}_{2}$ levels remains controversial. Both the type of anaesthetic circuit and the sam-

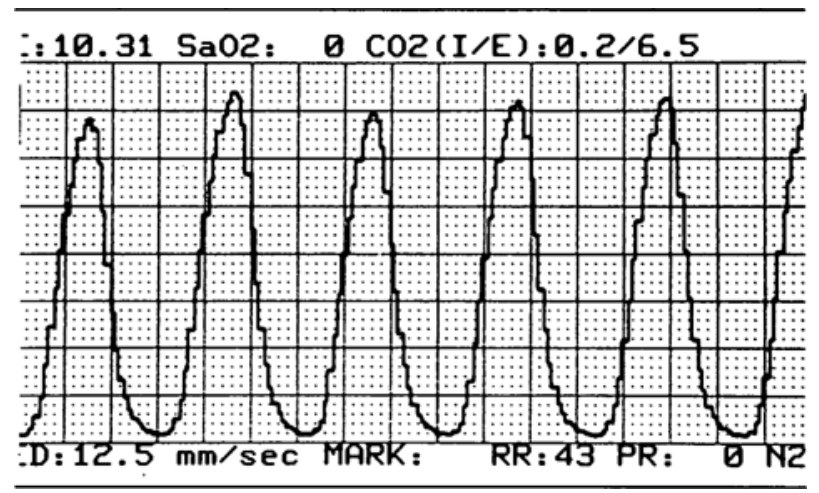

FIGURE 6 Capnogram.

pling site appear to influence the accuracy of end-tidal capnometry. ${ }^{14}$ It has been shown that in children weighing more than $12 \mathrm{~kg}$ with tracheas intubated and lungs ventilated by intermittent positive pressure ventilation using the same partial rebreathing circuit as in this study, both distal and proximal samples approximated $\mathrm{PaCO}_{2}$ values. ${ }^{5}$ In a study using single breath end-tidal $\mathrm{CO}_{2}$ as a means of estimating arterial $\mathrm{PCO}_{2}$ in infants and children, it was suggested that proximal measurements of $\mathrm{PETCO}_{2}$ accurately estimate $\mathrm{PaCO}_{2}$ provided that the fresh gas flow is interrupted during the period of measurement. ${ }^{9}$ Recently, in a laboratory study, it was reported that using a $3.5 \mathrm{~mm}$ endotracheal tube and fresh gas flows as large as $20 \mathrm{~L} \cdot \mathrm{min}^{-1}$ delivered by a Mapleson D circuit, dilution of the expired gases by the fresh gas flow occurred only as far as the connector. ${ }^{8}$ In another laboratory investigation using intubated rabbits and a Mapleson D circuit, it has been shown that $\mathrm{PeTCO}_{2}$ values are accurate if measured distally to the connector regardless of the mode of ventilation. ${ }^{10}$

There are several factors that may explain the differences between the results of this and previous studies. Firstly, the internal diameter of the shaft of the LMA $(7 \mathrm{~mm})$ is larger than an endotracheal tube used in a child of the same size. The LMA also maintains an artificial "pharyngeal" cavity which is bypassed by tracheal intubation. ${ }^{15}$ Secondly, the patients in this study were breathing spontaneously with a combination of high respiratory rates and low tidal volumes. This pattern of respiration increases the dilutional effect of the fresh gas flow due to the smaller expired volume of gases. Thirdly, a rapid respiratory rate causes inaccuracy in capnometer readings. ${ }^{16}$ The respiratory rates recorded in this group of patients varied from 40 to 70 breaths per min. This was in most cases fast enough to modify the recording pattern and affect phase III (plateau phase) of expiration. ${ }^{17}$ At high respiratory rates no good plateau phase could be observed (Figure 6). This would lead to an underestimation of the real $\mathrm{PETCO}_{2}$. 
The eight negative $\mathrm{PaCO}_{2}-\mathrm{PETCO}_{2}$ are more difficult to explain. In the case of cyclical respiration we took the highest $\mathrm{PETCO}_{2}$ for analysis. We may have overestimated the $\mathrm{PETCO}_{2}$ as it has been shown that the $\mathrm{PaCO}_{2}$ is close to the time-weighted average of alveolar $\mathrm{CO}_{2}$, which is lower than the $\mathrm{PETCO}_{2}$ in cyclical respiration. ${ }^{18}$ The other explanations for negative a-ETCO $\mathrm{CO}_{2}$ gradients (low respiratory rate, big tidal volume, sloping phase III) do not apply in children with rapid shallow respirations. ${ }^{19}$

The hypercapnia observed in our patients after approximately $30 \mathrm{~min}$ of spontaneous ventilation with an inspired halothane concentration of $2 \%$ may be explained as follows. Hypoventilation is produced by a concentration of halothane in excess of twice the minimal alveolar concentration. ${ }^{20,21}$ In a recent study investigating minute ventilation during mask halothane anaesthesia in infants and children it was shown that halothane reduces minute volume, tidal volume and increases breathing frequency. ${ }^{21}$ In addition, the magnitude of the dead space produced by the larger internal diameter of the laryngeal mask airway compared with the small tidal volume of spontaneously breathing children resulted in rebreathing at both the distal and tracheal sampling sites.

Several studies have identified sources of inaccuracy in measurements of PETCO ${ }_{2}$ in children. These have been avoided in the present study. Thus, the sampling aspiration rate of the end-tidal gas monitor was 150 $\mathrm{ml} \cdot \mathrm{min}^{-1}$ which has been shown to ensure an accurate estimate of the alveolar $\mathrm{CO}_{2}$ content without entrainment of fresh gas. ${ }^{22}$ Severinghaus pointed out that the availability of water-permeable catheters has led to an incorrect calibration practice. ${ }^{12}$ Our $\mathrm{PETCO}_{2}$ values have been corrected for BTPS.

In conclusion, the results of this study show that children under halothane anaesthesia and breathing spontaneously through a laryngeal mask airway become hypercapnic. The anaesthetist may not be aware of the level of hypercapnic as the $\mathrm{PETCO}_{2}$ measurements do not correlate well with $\mathrm{PaCO}_{2}$. The most accurate sample site for $\mathrm{PETCO}_{2}$ sampling is within the trachea. However, using this site defeats the purpose for using a laryngeal mask airway which is to provide a satisfactory airway without trespassing beyond the glottis.

\section{Acknowledgement}

The authors would like to thank Dr. J.E.S. Relton for his advice in the preparation of this manuscript.

\section{References}

1 Guidelines to the practice of anaesthesia as recommended by the Canadian Anaesthetists' Society. Suppl Can J

Anaesth 1993; 40: 10.

2 Gravenstein N, Lampotang S, Beneken JEW. Factors in- fluencing capnography in the Brain circuit. J Clin Monit 1985; 1: 6-10.

3 Kaplan RF, Paulus DA. Error in sampling of exhaled gases (Letter). Anesth Analg 1983; 62: 955-6.

4 Olsson SG, Fletcher R, Jonson B, Nordstrom L, Prakash $O$. Clinical studies of gas exchange during ventilatory support - a method using the Siemens-Elema $\mathrm{CO}_{2}$ analyser. Br J Anaesth 1980; 52: 491-9.

5 Badgwell JM, McLeod ME, Lerman J, Creighton RE. End-tidal $\mathrm{PCO}_{2}$ measurements sampled at the distal and proximal ends of the endotracheal tube in infants and children. Anesth Analg 1987; 66: 959-64.

6 Badgwell JM, Heavner JE, May WS, Goldthorn JF, Lerman J. End-tidal $\mathrm{PCO}_{2}$ monitoring in infants and children ventilated with either a partial rebreathing or a nonrebreathing circuit. Anesthesiology 1987; 66: 405-10.

7 Hillier SC, Badgwell JM, McLeod ME, Creighton RE, Lerman J. Accuracy of end-tidal $\mathrm{PCO}_{2}$ measurements using a sidestream capnometer in infants and children ventilated with the Sechrist infant ventilator. Can J Anaesth 1990; 37: 318-21.

8 Halpern L, Bissonnette $B$. Visualizing the mixing of fresh gas and expired gas in the Mapleson D circuit: a laboratory study. Anesthesiology 1991; 75: A421.

9 Bissonnette $B$, Lerman $J$. Single breath end-tidal $\mathrm{CO}_{2}$ estimates of arterial $\mathrm{PCO}_{2}$ in infants and children. Can $\mathrm{J}$ Anaesth 1989; 36: 110-2.

10 Rich GF, Sullivan MP, Adams JM. Is distal sampling of end-tidal $\mathrm{CO}_{2}$ necessary in small subjects? Anesthesiology 1990; 73: 265-8.

11 Rose DK, Byrick RJ, Froese AB. Carbon dioxide elimination during spontaneous ventilation with a modified Mapleson D system: studies in a long model. Can Anaesth Soc $\mathbf{J}$ 1978; 25: 353-65.

12 Severinghaus $J W$. Water vapor calibration errors in some capnometers: respiratory conventions misunderstood by manufacturers? Anesthesiology 1989; 70: 996-8.

13 Bland JM, Altman DG. Statistical methods for assessing agreement between two methods of clinical measurement. Lancet 1986; 307-10.

14 Kirpalani H, Kechagias S, Lerman J. Technical and clinical aspects of capnometry in neonates. J Med Eng Technol 1991; 15: 154-61.

15 Nunn JF. Applied Respiratory Physiology. 2nd Ed. London: Butterworths \& Co Ltd., 1977.

16 Sasse FJ. Can we trust end-tidal carbon dioxide measurements in infants? J Clin Monit 1985; 1: 147-8.

17 Fletcher $R$, Jonson B. Prediction of the physiological dead space/tidal volume ratio during anaesthesia/IPPV from simple pre-operative tests. Acta Anaesthesiol Scand 1981; 25: 58-62.

18 Piiper $J$. Blood-gas equilibrium of carbon dioxide in lungs: a continuing controversy. J Appl Physiol 1986; 60: 1-8. 
19 Fletcher $R$, Jonson $B$. Deadspace and the single breath test for carbon dioxide during anaesthesia and artificial ventilation. Effects of tidal volume and frequency of respiration. Br J Anaesth 1984; 56: 109-19.

20 Wren WS, Allen P, Synnott A, O'Keeffe D, O'Griofa P. Effects of halothane, isoflurane and enflurane on ventilation in children. Br J Anaesth 1987; 59: 399-409.

21 Brown KA, Bissonnette B, Holtby $H$, Ein $S$, Shandling $B$. Minute ventilation during mask halothane anaesthesia in infants and children. Can J Anaesth 1993; 40; 2: 112-8.

22 Gravenstein $N$. Capnometry in infants should not be done at lower sampling rates (Letter). J Clin Monit 1989; 5:

63-4. 